\title{
Direct Hemoperfusion with a Cytokine-Adsorbing Device for the Treatment of Persistent or Severe Hypercytokinemia: A Pilot Study
}

\author{
Y. Kobe ${ }^{a}$ S. Oda ${ }^{a} \quad$ K. Matsuda ${ }^{b}$ M. Nakamura ${ }^{a} \quad$ H. Hirasawa ${ }^{a}$ \\ a Department of Emergency and Critical Care Medicine, Graduate School of Medicine, Chiba University, Chiba, Japan \\ ${ }^{b}$ Department of Emergency and Critical Care Medicine, Yamanashi University Hospital, Yamanashi, Japan
}

\section{Key Words}

Hypercytokinemia $\cdot$ Cytokine-adsorbing device $\cdot$ Rapid cytokine assay

\begin{abstract}
Background/Aims: Cytokine overproduction has been noted during the aggravation of clinical conditions. Countermeasures to control hypercytokinemia are therefore important in critical care. We investigated the clinical efficacy of hemoadsorption therapy using a new cytokine-adsorbing device in critically ill patients with persistent or severe hypercytokinemia. Methods: Direct hemoperfusion using the CYT-860, a cytokine-adsorber column (CYT-860-DHP), was performed in critically ill patients with hypercytokinemia. To evaluate the efficacy of CYT-860-DHP, changes in pathological and clinical parameters were examined. Results: Seven patients with hypercytokinemia and a SOFA score of $\geq 5$ underwent CYT-860-DHP treatment. Four patients survived 28 days after CYT-860-DHP treatment. Significant decreases in blood levels of cytokines were observed. $\mathrm{PaO}_{2} / \mathrm{F}_{1} \mathrm{O}_{2}$ improved significantly. Conclusion: The possibility that CYT860-DHP treatment can reduce blood cytokine levels and thereby improve the general condition of patients was suggested. These findings warrant the initiation of a prospective randomized trial to evaluate the clinical efficacy of CYT-860DHP treatment.

Copyright $\odot 2007$ S. Karger AG, Basel
\end{abstract}

\section{KARGER}

Fax +4161306 1234 E-Mail karger@karger.ch www.karger.com

\section{Introduction}

It has recently been recognized that the overproduction of cytokines induced by various type of insults plays an important role in the pathophysiology of critically illness [1]. The overproduction of various cytokines has been reported, particularly during the aggravation of acute illness, and persistent hypercytokinemia reported to develop to multiple organ failure (MOF) with poor outcome [2].

In the treatment of diseases with this type of hypercytokinemia, it is considered important to restore cytokine balance by suppressing excess production of both proand anti-inflammatory cytokines [3]. Blood purification techniques have been extensively applied to MOF as well as other critical illnesses with various pathological features, and their usefulness in critical care is widely recognized [4]. Non-selective removal of multiple mediators of critical illnesses instead of selective removal of a single, putatively causative mediator has been proposed as a principal mechanism of the clinical efficacy of such techniques $[5,6]$. We have reported that continuous hemodiafiltration using a polymethylmethacrylate (PMMA) membrane hemofilter (PMMA-CHDF) non-selectively, efficiently, and continuously removed humoral mediators such as overproduced cytokines in vivo, mainly by adsorption [7].

Unfortunately, however, some cases of hypercytokinemia are refractory to control by conventional PMMA-

Yoshiro Kobe, $\mathrm{MD}, \mathrm{PhD}$

Department of Emergency and Critical Care Medicine

Graduate School of Medicine, Chiba University

1-8-1 Inohana, Chuo-ku, Chiba 260-8677 (Japan)

Tel. +81 43222 7171, Fax +81 43226 2371, E-Mail y-kobe@umin.ac.jp 
$\mathrm{CHDF}$, and require a more potent method of cytokine removal. We have therefore developed the CYT-860, a new cytokine-adsorbing device applicable to cytokine adsorption therapy [8]. We report here cytokine adsorption therapy using this new device in critically ill patients with persistent or severe hypercytokinemia.

\section{Materials and Methods}

\section{Patients}

Seven critically ill patients with persistent or severe hypercytokinemia admitted to the ICU of a university teaching hospital (Chiba University Hospital) between August 2004 and March 2006 were included in this study. Persistent or severe hypercytokinemia was defined as follows: (1) systemic inflammatory response syndrome (SIRS) persisting for $\geq 4$ days with either an IL- 6 blood level of $\geq 1,000 \mathrm{pg} / \mathrm{ml}$ or an IL- 8 blood level of $\geq 500$ $\mathrm{pg} / \mathrm{ml}$; (2) SIRS with either an IL- 6 blood level of $\geq 5,000 \mathrm{pg} / \mathrm{ml}$ or an IL- 8 blood level of $2,500 \mathrm{pg} / \mathrm{ml}$, or (3) sequential organ failure assessment (SOFA) score of $\geq 5$ with either an IL- 6 blood level of $\geq 1,000 \mathrm{pg} / \mathrm{ml}$ or an IL-8 blood level of $\geq 500 \mathrm{pg} / \mathrm{ml}$.

Direct hemoperfusion using the CYT-860 (CYT-860-DHP) was initiated when the patient met any of the above three criteria and the data were excluded if the patient received steroids or underwent PMMA-CHDF during CYT-860-DHP treatment, since either of these interventions may affect blood cytokine levels. This study was approved by the Institutional Ethics Committee. Written informed consent was obtained from representatives of all study participants prior to enrollment.

\section{Adsorbent}

The adsorbent used to construct the CYT-860 (Toray Industries, Inc., Tokyo, Japan) was prepared by chemical modification of a polystyrene-based conjugated fiber reinforced with polypropylene and originally developed as an exotoxin adsorber [9]. Polystyrene is used as a fiber filter material packed in a polymyxin B-immobilized hemoperfusion cartridge for endotoxin removal [10]. 4-(4-\{12-[N'-(4-chlorophenyl)ureylene]-1,4,7,10-tetraazadodecylene -acetylacetoamido) groups are covalently immobilized on the polystyrene component of the adsorbent fiber as adsorption ligands. Protein adsorption onto this matrix may involve pairwise hydrogen bonding between a urea bond or an amino group in the ligand moiety and a carboxyl group, an amino group, or an amide bond in the protein molecule. The adsorption ability of various molecules, such as cytokines, superantigens, and other proteins was examined by in-vitro batchwise adsorption, incubating for $120 \mathrm{~min}$. The adsorption rates were 20, 97, 92, 99, 83, 96, and $84 \%$ for TNF- $\alpha$, IL- $1 \beta$, IL- 6 , IL- 8 , IL-10, TSST- 1 , and $\beta_{2}$-microglobulin, respectively [9].

\section{Operating Conditions for DHP and CHDF}

Vascular access was obtained by placing a flexible double-lumen catheter in the internal jugular vein or the femoral vein for blood removal/return at a blood flow rate of $100 \mathrm{ml} / \mathrm{min}$. Nafamostat mesilate (Futhan; Torii Pharmaceutical Co. Ltd, Tokyo, Japan) was used as an anticoagulant and administered from an injection port on the inlet side of the cytokine adsorber column at a rate of $10-20 \mathrm{mg} / \mathrm{h}$ to maintain an activated coagulation time for blood in systemic circulation of 150-180 s. As a rule, a CYT860 column was performed in the extracorporeal circuit for 24 consecutive hours, and was then replaced by a new one. When CHDF had to be performed in combination with CYT-860-DHP to treat renal failure as a complication, a CYT-860 column and a hemofilter were connected in series in the extracorporeal circuit. A polysulfone or cellulose triacetate membrane hemofilter incapable of cytokine removal was used for CHDF to permit accurate evaluation of the cytokine removing capacity of the CYT-860 column (fig. 1).

\section{Criteria for Termination of CYT-860-DHP Treatment}

CYT-860-DHP treatment was terminated if both of the following criteria were met: (1) recovery from SIRS, and (2) an IL-6 blood level $<1,000 \mathrm{pg} / \mathrm{ml}$ and an IL-8 blood level $<500 \mathrm{pg} / \mathrm{ml}$. CYT-860-DHP treatment was discontinued on the 8th day after initiation of DHP treatment, even if the patient failed to meet either of the above criteria.

\section{Measurements and Outcome Measures}

The leukocyte count, heart rate, respiratory rate, body temperature, $\mathrm{F}_{\mathrm{I}} \mathrm{O}_{2}, \mathrm{PaO}_{2}$, platelet count, serum total bilirubin level, and serum creatinine level were determined immediately before initiation of the first CYT-860-DHP session, at 06:00 a.m. every morning during the CYT-860-DHP treatment period, and at the end of each CYT-860-DHP treatment. Glasgow Coma Scale (GCS), $\mathrm{PaO}_{2} / \mathrm{F}_{\mathrm{I}} \mathrm{O}_{2}$ ratio, and SOFA score were also assessed for individual patients. Doses of dopamine, dobutamine, and noradrenaline were recorded (all in $\mu \mathrm{g} / \mathrm{kg} / \mathrm{min}$ ) to compare the total dose of all catecholamines used in different patients by calculating the catecholamine index, retrospectively. Catecholamine index was calculated with the following formula:

Catecholamine index $=$ dopamine dose + dobutamine dose + $100 \times$ noradrenaline dose

When a patient expected to meet the initiation criteria for CYT-860-DHP treatment was admitted to the ICU, blood samples were collected and subjected to rapid cytokine assay by ELISA (dipstick ELISA) for blood levels of IL- 6 and IL-8 to determine whether he or she in fact met the criteria. Once CYT-860-DHP was started, blood samples were collected at intervals of $24 \mathrm{~h}$ and assayed for blood levels of IL- 6 and IL- 8 to determine whether the criteria for termination of CYT-860-DHP treatment had been met. All blood samples used for the judgment whether to initiate or terminate CYT-860-DHP treatment were stored at $-80^{\circ} \mathrm{C}$ for subsequent reassessment of blood levels of IL- 6 and IL- 8 by ELISA. To assess the performance of the CYT- 860 columns, blood samples were collected 3, 6, 12, and $23 \mathrm{~h}$ after the first CYT-860DHP or after placement of a new CYT- 860 column in the blood circuit and stored at $-80^{\circ} \mathrm{C}$ for subsequent reassessment of the blood levels of IL-6, IL-8, and IL-10 by ELISA. Blood samples were also drawn from the blood circuit at the inlet and outlet of the CYT-860 column $3 \mathrm{~h}$ after installation and were stored at $-80^{\circ} \mathrm{C}$ for precise measurement of blood levels of IL-6, IL-8, and IL-10 by ELISA to calculate the clearance of cytokines using the following formula:

$$
\text { Cytokine clearance }=\left[\left(\mathrm{CB}_{\mathrm{i}}-\mathrm{CB}_{\mathrm{o}}\right) / \mathrm{CB}_{\mathrm{i}}\right] \times \mathrm{QB},
$$




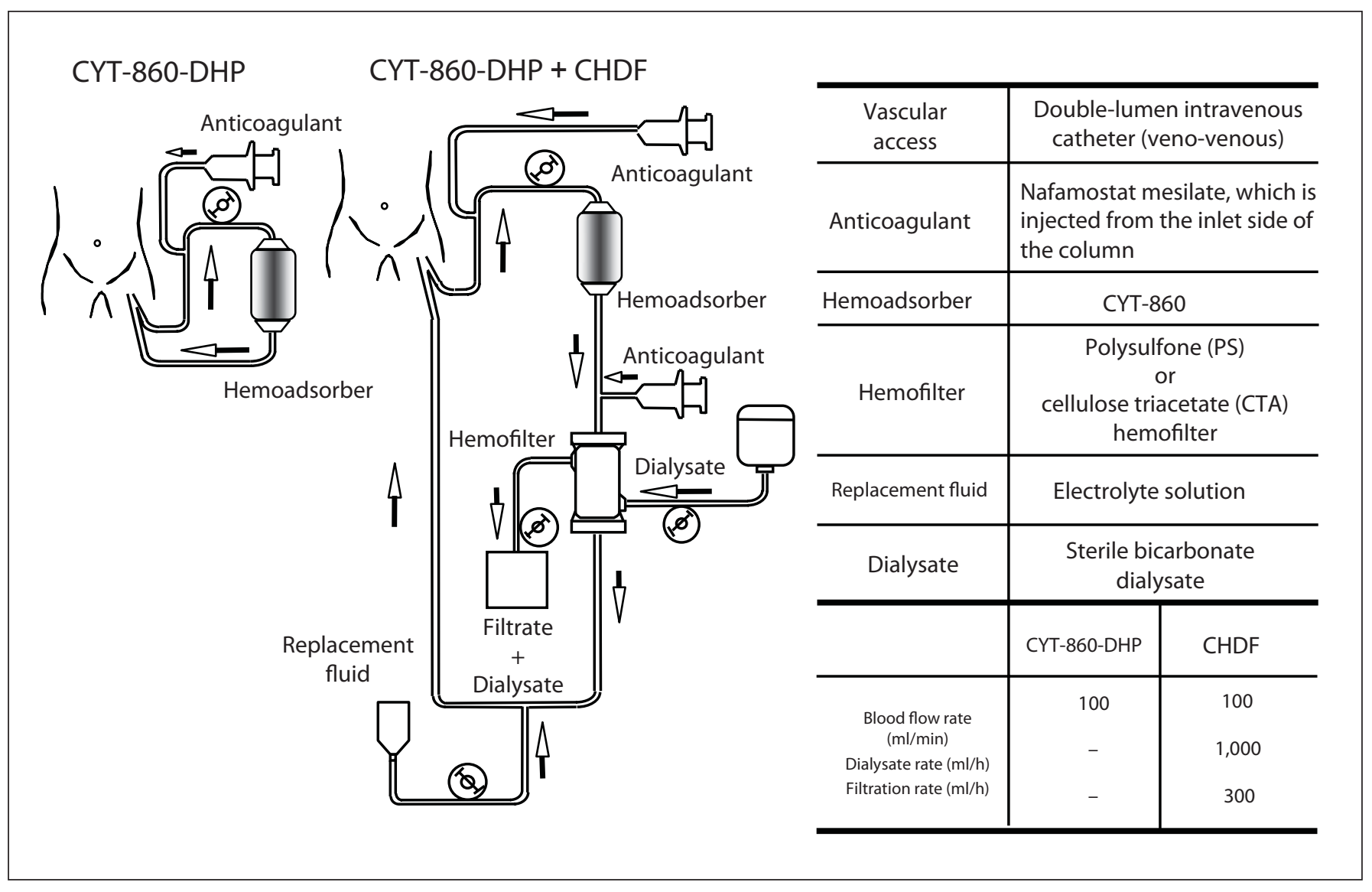

Fig. 1. Flow diagram and operating conditions in CYT-860-DHP treatment.

where $\mathrm{QB}=$ blood flow rate $(\mathrm{ml} / \mathrm{min}), \mathrm{CB}_{\mathrm{i}}=$ blood cytokine level at the inlet of the CYT-860 column, and $\mathrm{CB}_{\mathrm{o}}=$ blood cytokine level at the outlet of the CYT-860 column.

The total number of CYT-860 columns used and duration of CYT-860-DHP treatment were recorded for each patient, as well as the presence or absence of concomitant CHDF with the type of hemofilter used. Clinical outcome at 28 days after the initiation of CYT-860-DHP treatment was also recorded. Complications encountered during the CYT-860-DHP treatment period were examined to assess the clinical safety of this treatment.

\section{Rapid Cytokine Assay by ELISA}

Rapid cytokine assay was performed using the Nunc ImmunoStick System for dipstick ELISA (Nunc, Roskilde, Denmark), in which a sandwich ELISA antigen-antibody reaction occurs on the surface of polystyrene sticks or on paddles exposed to reagents by immersion [11].

Purified polyclonal anti-IL-6 antibody or anti-IL-8 antibody was diluted in phosphate-buffered saline (pH 7.2) (PBS) to a concentration of $2 \mathrm{mg} / \mathrm{ml}$, and $0.5-\mathrm{ml}$ aliquots were added to the immunostick tubes. After the paddle was inserted into the tube, the entire immunostick system was incubated for $18 \mathrm{~h}$ at $4^{\circ} \mathrm{C}$. Unbound antibody was removed by aspiration and then the paddle was treated for $2 \mathrm{~h}$ at $25^{\circ} \mathrm{C}$ with $1 \mathrm{ml}$ of PBS containing $0.5 \%$ bovine serum albumin fraction V (BSA) (Serological Proteins Inc., Kankakee, Ill., USA). BSA solution was then removed by aspiration and the paddle was washed twice with distilled water.

Serum samples were added in $200-\mu$ l aliquots to the test tubes, each of which contained $200 \mu \mathrm{l}$ of reaction buffer (PBS, pH 7.2, containing $2 \mu \mathrm{g} / \mathrm{ml}$ horseradish peroxidase-conjugated anti-IL-6 or anti-IL-8 monoclonal antibodies, $0.25 \%$ BSA, $0.05 \%$ Tween-20, and $10 \mu \mathrm{g} / \mathrm{ml}$ goat IgG). Then the antibody-coated paddles were immersed into this mixture and incubated for $30 \mathrm{~min}$ at $25^{\circ} \mathrm{C}$. Unreacted reagents were removed, and then paddles were rinsed three times with distilled water. Substrate solution containing 3,3',5,5'-tetramethylbenzidine (Promega Corp., Madison, Wisc., USA) was then added in 1-ml aliquots and incubated for $15 \mathrm{~min}$ at $25^{\circ} \mathrm{C}$. The enzyme reaction was terminated by washing the paddles with distilled water. The color values of the immunosticks were read with a spectrocolorimeter (JX7-500, Color Techno Systems Co., Tokyo, Japan), and color differences were calculated automatically from these values, which correlated with the cytokine concentration. Serial dilutions of each cytokine in the serum of healthy human volunteers were used as concentration standards [11]. This rapid cytokine assay by ELISA is original and is first published in this paper. 
Table 1. Characteristics of the patients treated with CYT-860-DHP

\begin{tabular}{|c|c|c|c|c|c|c|c|c|c|c|c|}
\hline \multirow[t]{2}{*}{ Case } & \multirow[t]{2}{*}{ Age } & \multirow[t]{2}{*}{ Sex } & \multirow[t]{2}{*}{ Underlying disease } & \multirow{2}{*}{$\begin{array}{l}\text { Other treatment } \\
\text { (all include } \\
\text { antibiotics) }\end{array}$} & \multicolumn{3}{|c|}{ Before CYT-860-DHP treatment } & \multirow{2}{*}{$\begin{array}{l}\text { Number of } \\
\text { CYT-860 } \\
\text { columns } \\
\text { used }\end{array}$} & \multirow{2}{*}{$\begin{array}{l}\text { Duration of } \\
\text { CYT-860-DHP } \\
\text { treatment, h }\end{array}$} & \multirow[t]{2}{*}{ CHDF } & \multirow{2}{*}{$\begin{array}{l}\text { Outcome at } \\
\text { the } 28 \text { th day }\end{array}$} \\
\hline & & & & & $\begin{array}{l}\text { IL-6 blood } \\
\text { level, pg/ml }\end{array}$ & $\begin{array}{l}\text { SOFA } \\
\text { score }\end{array}$ & failing organs & & & & \\
\hline 1 & 72 & M & $\begin{array}{l}\text { burn wound sepsis } \\
\text { 2nd degree } 35 \% \text { BSA } \\
\text { 3rd degree } 11 \% \text { BSA }\end{array}$ & $\begin{array}{l}\text { excision, skin } \\
\text { grafting }\end{array}$ & 3,770 & 16 & $\begin{array}{l}\text { brain, heart, } \\
\text { lung, liver, } \\
\text { kidney }\end{array}$ & 2 & 17 & PS-CHDF & dead \\
\hline 2 & 72 & M & $\begin{array}{l}\text { acute obstructive sup- } \\
\text { purative cholangitis }\end{array}$ & EST, PTBD & 76,600 & 17 & heart & 7 & 143 & PS-CHDF & survived \\
\hline 3 & 55 & M & $\begin{array}{l}\text { ARDS after surgery for } \\
\text { oropharyngeal cancer }\end{array}$ & ventilator & 4,800 & 8 & lung & 4 & 64 & - & survived \\
\hline 4 & 74 & M & aspiration pneumonia & ventilator & 1,660 & 7 & brain, lung & 5 & 63 & - & dead \\
\hline 5 & 82 & $\mathrm{~F}$ & pyelonephritis & $\begin{array}{l}\text { ureteral stent } \\
\text { insertion }\end{array}$ & 29,100 & 10 & heart & 3 & 45 & - & survived \\
\hline 6 & 70 & $\mathrm{~F}$ & MRSA pneumonia & ventilator & 15,300 & 16 & $\begin{array}{l}\text { brain, heart, } \\
\text { lung, kidney }\end{array}$ & 1 & 14 & PS-CHDF & dead \\
\hline 7 & 57 & $\mathrm{~F}$ & cervical abscess & $\begin{array}{l}\text { abscess } \\
\text { drainage }\end{array}$ & 31,800 & 17 & $\begin{array}{l}\text { brain, heart, } \\
\text { lung, kidney }\end{array}$ & 6 & 141 & $\begin{array}{l}\text { CTA- } \\
\text { CHDF }\end{array}$ & survived \\
\hline $\begin{array}{l}\text { Mean } \\
\pm S D\end{array}$ & & & & & $\begin{array}{l}23,300 \\
\pm 26,500\end{array}$ & $\begin{array}{l}12.93 \\
\pm 4.3\end{array}$ & & $\begin{array}{l}4.0 \\
\pm 2.2\end{array}$ & $\begin{array}{l}66.4 \\
\pm 46.9\end{array}$ & & \\
\hline
\end{tabular}

DHP = Direct hemoperfusion; SOFA = sequential organ failure assessment; BSA = body surface area; ARDS = acute respiratory distress syndrome; MRSA = methicillin-resistant Staphylococcus aureus; EST = endoscopic sphincterotomy; PTBD = percutaneous transhepatic biliary drainage; PS = polysulfone; $\mathrm{CTA}=$ cellulose triacetate; $\mathrm{CHDF}=$ continuous hemodiafiltration; $\mathrm{SD}=$ standard deviation.

\section{Statistical Analysis}

All measurement values are expressed as the mean \pm SD. The significance of differences in clinical parameters before to after CYT-860-DHP treatment was tested by the Student t test, with $\mathrm{p}$ values $<0.05$ considered significant.

\section{Results}

\section{Patients}

Table 1 summarizes the characteristics and outcomes of the 7 patients included in this study. Patient 1 had $46 \%$ total body surface area burn (second degree 35\%, third degree 11\%). Excision surgery and skin grafting were performed on the 7th, 13th and 16th ICU days, respectively. However, his general condition deteriorated due to sepsis. Therefore, CYT-860-DHP was started on the 16th ICU day. Patient 2 had acute obstructive suppurative cholangitis due to common bile duct stone and was treated with endoscopic sphincterotomy and percutaneous transhepatic biliary drainage before CYT-860-DHP. Patient 3 developed acute respiratory distress syndrome 4 days after operation for oropharyngeal cancer. Therefore, CYT-860-DHP was started 5 days after surgery. Patient 4 was admitted to the ICU for severe respiratory failure due to aspiration pneumonia and his GCS was E4VTM6 when CYT-860-DHP was started. However, his consciousness level gradually deteriorated during the CYT-860-DHP treatment. He was diagnosed as having fatal brainstem infarction by MRI image and died on the 14th ICU day. Patient 5 had left pyelonephritis and a stent was inserted in her left ureter before CYT-860-DHP treatment. Escherichia coli was isolated in her blood and urine. Patient 6 had septic shock induced by MRSA pneumonia and could not recover from shock state. Her general condition deteriorated rapidly and she died. Therefore, the CYT-860-DHP treatment was ended at 14 h. Patient 7 had cervical abscess and Streptococcus pyogenes was isolated in her cervical wound. Surgical drainage for cervical abscess was performed before starting CYT-860-DHP. All patients met initiation criterion 3 (i.e., a SOFA score of $\geq 5$ with either an IL- 6 blood level of $\geq 1,000 \mathrm{pg} / \mathrm{ml}$ or an IL- 8 blood level of $\geq 500 \mathrm{pg} /$ $\mathrm{ml})$. The baseline IL- 6 blood level exceeded $10,000 \mathrm{pg} / \mathrm{ml}$ in 4 patients, with a mean of $23,300 \mathrm{pg} / \mathrm{ml}$ for all $7 \mathrm{pa}-$ tients. The baseline SOFA score exceeded 15 in 4 patients, with a mean of 12.9 for all 7 patients. The mean duration of CYT-860-DHP treatment was $66.4 \mathrm{~h}$, and the mean number of CYT-860 columns used during the treatment period was four.

CHDF was concomitantly performed in 4 patients with renal failure as a complication. Polysulfone membrane filters were used for CHDF in 3 patients, while cel- 
Fig. 2. Changes in blood levels of IL- 6 dur-

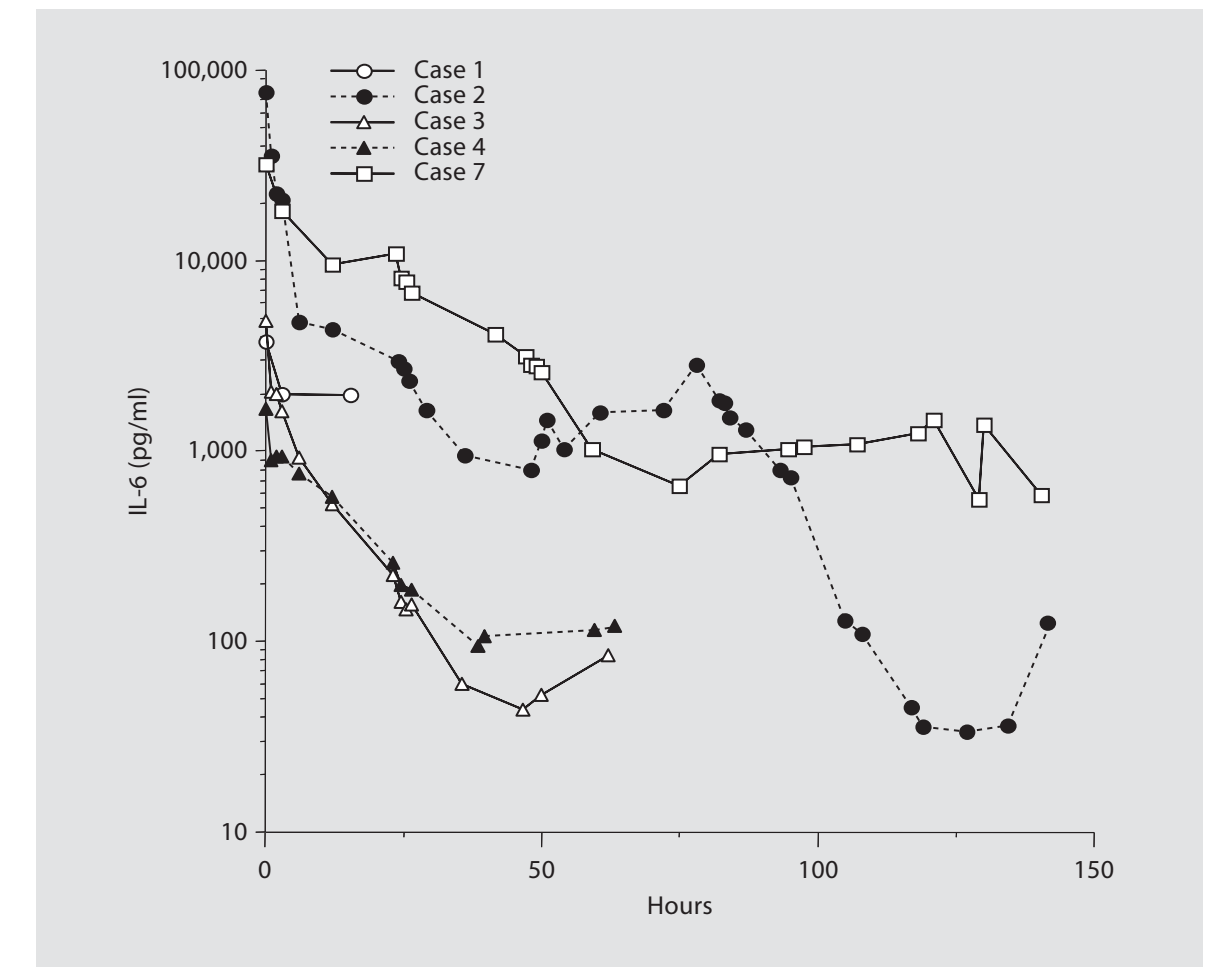
ing CYT-860-DHP treatment.

lulose triacetate membrane filters were used in 1 other patient. Four patients survived 28 days after the initiation of CYT-860-DHP. Of the 3 patients who died within 28 days after initiation of CYT-860-DHP treatment (cases 1, 4 , and 6), patient 4 died of stroke that had developed prior to initiation of CYT-860-DHP treatment and was not due to organ failure associated with hypercytokinemia. In the case of patient 5 who survived, it was later found that a steroid had been administered during the CYT860-DHP treatment period to treat interstitial pneumonia that had developed prior to the initiation of CYT-860DHP treatment. In patient 6, who died, the duration of CYT-860-DHP treatment was only $14 \mathrm{~h}$ and this was considered too brief to allow assessment of clinical efficacy of this treatment. Accordingly, case 5 and 6 were excluded from further analysis except cytokine clearance. The results presented below were obtained from the remaining 5 cases.

\section{Cytokine Clearance}

The clearance of IL- 6 observed $3 \mathrm{~h}$ after initiation of CYT-860-DHP treatment or $3 \mathrm{~h}$ after changing to a new CYT- 860 columns was $8.1 \pm 5.1 \mathrm{ml} / \mathrm{min}(\mathrm{n}=10)$, while those of IL- 8 and IL-10 were $6.2 \pm 9.6 \mathrm{ml} / \mathrm{min}(\mathrm{n}=10)$ and $9.8 \pm 7.5 \mathrm{ml} / \mathrm{min}(\mathrm{n}=10)$, respectively.

\section{Changes in Blood Cytokine Levels}

Figures 2-4 illustrate the changes in blood cytokine levels during CYT-860-DHP treatment. Significant decreases in the blood levels of IL-6 $(23,700 \pm 32,000$ to 650 $\pm 760, \mathrm{p}<0.05)$, IL-8 $(1,270 \pm 1,970$ to $33.0 \pm 27.2, \mathrm{p}<$ $0.05)$ and IL-10 (769 $\pm 1,070$ to $114 \pm 166, \mathrm{p}<0.05)$ were observed after the CYT-860-DHP treatment period.

\section{Change in Number of Patients with SIRS}

All five patients had SIRS prior to the initiation of CYT-860-DHP treatment and 2 of 5 patients recovered from SIRS after the treatment.

\section{Changes in $\mathrm{PaO}_{2} / \mathrm{F}_{\mathrm{I}} \mathrm{O}_{2}$, Catecholamine Index, and SOFA Score}

$\mathrm{PaO}_{2} / \mathrm{F}_{\mathrm{I}} \mathrm{O}_{2}$ was changed from $173 \pm 43.4$ to $223 \pm 113$ $(\mathrm{p}<0.05)$, catecholamine index from $8.8 \pm 6.5$ to $2.4 \pm$ 5.4 (n.s.), and SOFA score from $13.4 \pm 4.8$ to $11.8 \pm 4.2$, respectively (n.s.).

\section{Complications}

No significant complications of CYT-860-DHP were noted during the treatment period. A decrease in mean platelet count was observed $(90,000 / \mu \mathrm{l}$ at baseline vs. $69,000 / \mu l$ after treatment), but was not significant. 
Fig. 3. Changes in blood levels of IL-8 during CYT-860-DHP treatment.
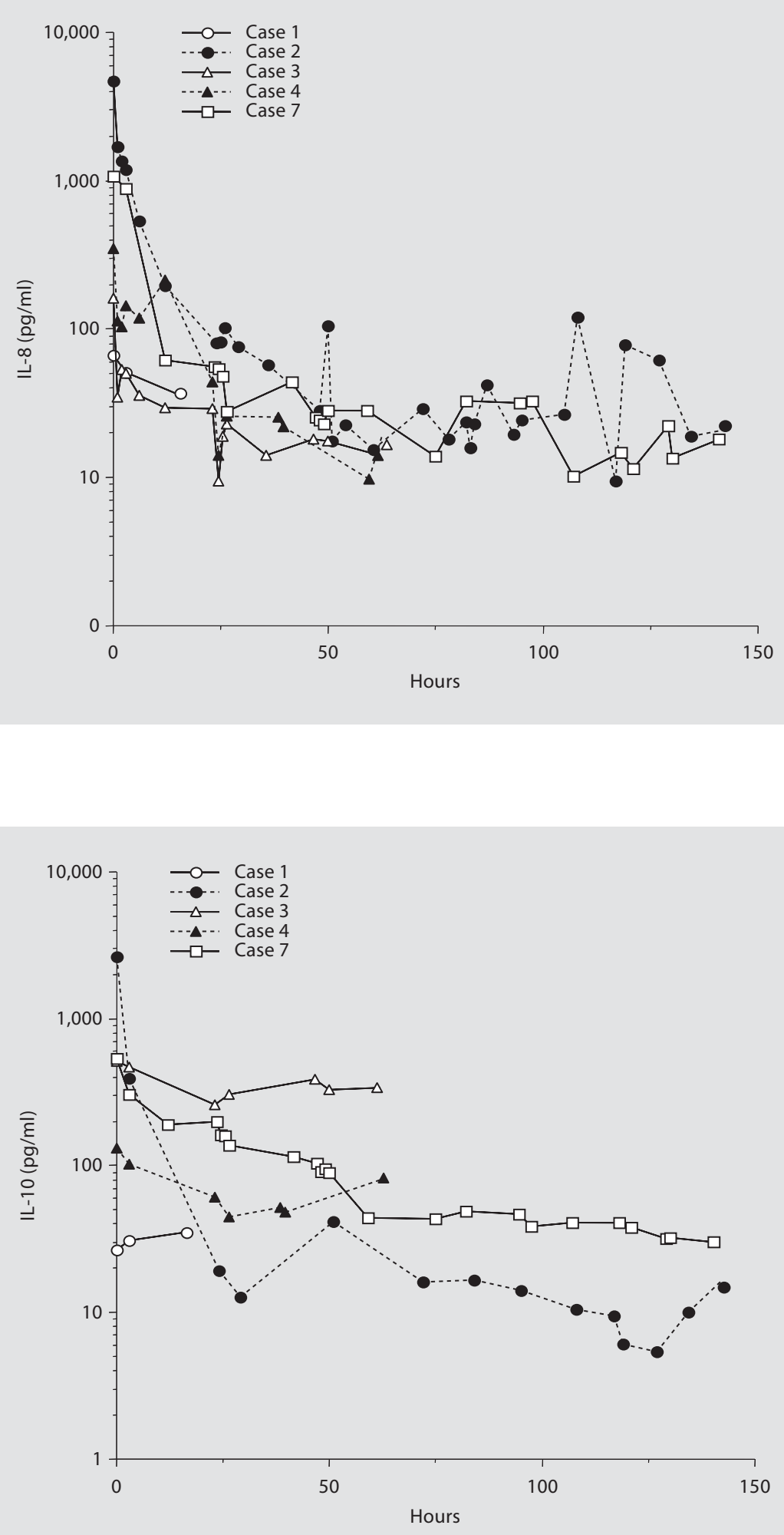

Fig. 4. Changes in blood levels of IL-10 during CYT-860-DHP treatment. 


\section{Discussion}

It is widely recognized that humoral mediators, including cytokines, play important roles in the pathophysiology of critical illness [1]. Sepsis, defined as SIRS caused by infection, is a typical critical illness associated with the hypercytokinemia induced by cytokine overproduction, and persistent hypercytokinemia may often proceed to MOF $[2,3]$.

The clinical usefulness of blood purification in the treatment of persistent hypercytokinemia has recently been recognized [4]. Non-selective clearance of multiple mediators of critical illnesses rather than the selective removal of a putatively causal single mediator has been proposed as the principal reason for the clinical efficacy of this treatment $[5,6]$.

Vincent et al. [12] reported the result of a multicenter controlled trial using polymyxin B-immobilized endotoxin removal hemoperfusion cartridge, which could remove endotoxin in severe sepsis or septic shock. However, the difference in the reduction of blood endotoxin levels was not significant between the groups. We believe that hypercytokinemia plays a causative role in the development of sepsis and septic MOF, and that endotoxin is only a small part of them. Therefore, we consider that CYT-860-DHP, a non-selective cytokine adsorber, could be a useful modality for sepsis and septic MOF and that it could be also effective for various diseases with hypercytokinemia such as severe acute pancreatitis adding to sepsis.

Four kinds of cytokine adsorbers have thus far been developed: the CYT-860 [8, 9, 13, 14], Cytosorb [15, 16], CTR [17, 18], and MPCF-X [19]; but there are very few clinical reports of these four adsorbers [18]. The CYT860 , which was evaluated in the present study, was originally developed as an exotoxin adsorber and found during the course of development to adsorb cytokines as well. The in-vitro adsorption rate was low for TNF- $\alpha$ (due to the higher molecular weight of its physiological form, a trimer composed of three monomers each with a molecular weight of $17 \mathrm{kDa}$, than those of other cytokines) but exceeded $90 \%$ for IL-1 $\beta$, IL-6, and IL-8 [9]. DHP using CYT-860 has been reported in laboratory animal models. Fenwick et al. [13] performed blood purification using CYT-860 in rats receiving an intraperitoneal injection of $S$. pyogenes (group A $\beta$-hemolytic streptococci), and reported significant improvement of the survival rate in the treatment group compared with the control group $36 \mathrm{~h}$ after the initiation of treatment (90 vs. $20 \%$, $\mathrm{p}<0.01)$. They also found that this treatment inhibited increases in the blood bacterial count, plasma exotoxin level, and plasma IL-6 level [13]. Miwa et al. [14] performed CYT-860-DHP treatment in a swine sepsis model prepared by the administration of toxic shock syndrome toxin-1 (TSST-1) and endotoxin, and reported significant improvement in the survival rate in the treatment group compared with the control group $24 \mathrm{~h}$ after the initiation of treatment $(60$ vs. $0 \%, p<0.01)$. CYT- 860 DHP was also performed in a rabbit sepsis model prepared by the administration of TSST-1 and endotoxin, and significantly improved the survival rate in the treatment group compared with the control group 14 days after initiation of treatment [8]. These observations of high in-vitro cytokine adsorption rates as well as the excellent efficacy in septic animals prompted us to attempt the first clinical application of CYT-860 in human subjects in the present study.

Of the 7 patients undergoing CYT-860-DHP in the present study, 2 were excluded due to steroid administration during the treatment period or because the treatment period before death was too short for evaluation except clearance study. The mean clearance of IL-6, IL-8, and IL-10 observed $3 \mathrm{~h}$ after initiation of CYT-860-DHP were $8.1,6.2$, and $9.8 \mathrm{ml} / \mathrm{min}$, respectively. These values measured in vivo are much lower than the reported invitro adsorption rates for these cytokines. These differences may be ascribed to the differences between the measurement conditions of the in-vitro and in-vivo cytokine removal rate: in-vitro values were obtained in batchwise adsorption tests with the adsorption matrix suspended in serum, while the in-vivo values in the present clinical study were obtained by circulating whole blood through a cartridge containing the adsorption matrix. Despite the relatively low removal rates observed in vivo, significant decreases in blood levels of IL-6, IL-8, and IL10 were observed following CYT-860-DHP treatment, demonstrating that continuous cytokine adsorption successfully decreased the blood levels of cytokines. In addition, CYT-860-DHP treatment improved $\mathrm{PaO}_{2} / \mathrm{F}_{\mathrm{I}} \mathrm{O}_{2}$ significantly and also reduced the catecholamine index. The percentage change in the catecholamine index before and after CYT-860-DHP demonstrated a significant decrease (from 100 to $24 \%, \mathrm{p}<0.05$ ), indicating that CYT-860DHP permitted a tapering of catecholamines (though not to a significant extent), and tended to improve the SOFA score. Since the lung is an organ susceptible to attack by inflammatory cells, a decrease in the blood levels of cytokines might ameliorate infiltration of inflammatory cells into the lung, leading to an improvement of $\mathrm{PaO}_{2} /$ $\mathrm{F}_{\mathrm{I}} \mathrm{O}_{2}$. The non-significant improvement of the SOFA 
score observed might be ascribed to the fact that a decrease in blood levels of cytokines does not lead to direct improvement of GCS, a parameter used for calculation of SOFA score. If necessary, treatment interventions such as drainage or surgical debridement were undertaken before enrollment to this study, therefore we considered that these interventions did not influence the efficacy of CYT-860-DHP. The observed survival on the 28th day in the present study is $57.1 \%(4 / 7)$ and the survival on the 28 th day in patients with hypercytokinemia such as IL-6 blood level $>10,000 \mathrm{pg} / \mathrm{ml}$ (mean SOFA score $12.4 \pm 4.6$ ) treated with conventional support including PMMACHDF in our ICU is $53.3 \%(16 / 30)$ [20]. This result suggests that CYT-860-DHP, a quite simple system of blood purification, was able to obtain equal clinical efficacy with the more complicated system of PMMA-CHDF. Thus, the present findings suggest the possibility that CYT-860-DHP treatment can improve pulmonary and circulatory function in critically ill patients with persistent or severe hypercytokinemia and thereby improve their general condition.

The common complications generally encountered during blood purification treatment include leukopenia and thrombocytopenia. In the present study, the leukocyte count increased after CYT-860-DHP treatment, with a concomitant but non-significant decrease in platelet count. No other complications of CYT-860-DHP treatment were observed, demonstrating that it applied safely in the clinical setting.

The present study has the following limitations: first, it was a small-scale pilot study including only 7 patients, and second, it was an uncontrolled study which did not include control subjects. Nevertheless, these findings would warrant a prospective randomized trial to further investigate the clinical efficacy of CYT-860-DHP treatment.

\section{References}

1 Balk RA: Pathogenesis and management of multiple organ dysfunction of failure in severe sepsis and septic shock. Crit Care Clin 2000;16:337-352.

-2 Spittler A, Razenberger M, Kupper H, Kaul M, Hackl W, Boltz-Nitulescu G, Fugger R, Roth E: Relationship between interleukin- 6 plasma concentration in patients with sepsis, monocyte phenotype, monocyte phagocytic properties, and cytokine production. Clin Infect Dis 2000;31:1338-1342.

3 Adrie C, Pinsky MR: The inflammatory balance in human sepsis. Intensive Care Med 2000;26:364-375.

$\checkmark 4$ Oda S, Hirasawa H, Shiga H, Nakanishi K, Matsuda K, Nakamura M: Continuous hemofiltration/hemodiafiltration in critical care. Ther Apher 2002;6:193-198.

$\checkmark 5$ Kellum JA, Venkataraman R: Blood purification in sepsis: an idea whose time has come? Crit Care Med 2002;30:1387-1388.

$\checkmark 6$ Matsuda K, Hirasawa H, Oda S, Shiga H, Nakanishi K: Current topics on cytokine removal technologies. Ther Apher 2001;5:306314.

-7 Hirasawa H, Oda S, Shiga H, Matuda K: Endotoxin adsorption or hemodiafiltration in the treatment of multiple organ failure. Curr Opin Crit Care 2000;6:421-425.

$\checkmark 8$ Miwa K, Fukuyama M, Ida N, Igarashi H, Uchiyama T: Preparation of a superantigenadsorbing device and its superantigen removal efficacies in vitro and in vivo. Int J Infect Dis 2003;7:21-26.
9 Miwa K, Shibayama N, Ida N, Kawabe Y, Ohzeki T: A novel blood purification therapy for the treatment of Gram-positive bacterial sepsis. Jpn J Apher 2005;24:244-249.

10 Shoji H: Extracorporeal endotoxin removal for the treatment of sepsis: endotoxin adsorption cartridge (Toraymyxin). Ther Apher 2003;7:108-114.

11 Rossi CL, Tsang VC, Pilcher JB: Rapid, lowtechnology field- and laboratory-applicable enzyme-linked immunosorbent assays for immunodiagnosis of Schistosoma mansoni. J Clin Microbiol 1991;29:1836-1841.

12 Vincent JL, Laterre PF, Cohen J, Burchardi $\mathrm{H}$, Bruining H, Lerma FA, Wittebole X, De Backer D, Brett S, Marzo D, Nakamura $H$ John S: A pilot-controlled study of a polymyxin B-immobilized hemoperfusion cartridge in patients with severe sepsis secondary to intra-abdominal infection. Shock 2005;23:400-405.

13 Fenwick P, Ryan C, Sriskandan S, Cohen J: Application of a rat model of streptococcal shock to evaluate on-line hemoperfusion and removal of circulating superantigens. Crit Care Med 2003;31:171-178.

14 Miwa K, Fukuyama M, Matsuno N, Shimada K, Ikeda K, Ikeda T: Physiological response to superantigen-adsorbing hemoperfusion in toxin-concentration-controlled septic swine. Blood Purif 2006;24:319-326.

15 Winchester JF, Kellum JA, Ronco C, Brady JA, Quartararo PJ, Salsberg JA, Levin NW: Sorbents in acute renal failure and the systemic inflammatory response syndrome. Blood Purif 2003;21:79-84.
16 Kellum JA, Song M, Vankataraman P: Hemoadsorption removes tumor necrosis factor, interleukin-6, and interleukin-10, reduces nuclear factor- $\kappa \mathrm{B}$ DNA binding, and improves short-term survival in lethal endotoxemia. Crit Care Med 2004;32:801-805.

17 Taniguchi T, Hirai F, Takemoto Y, Tsuda K, Yamamoto K, Inaba H, Sakurai H, Furuyoshi S, Tani N: A novel adsorbent of circulating bacterial toxins and cytokines. Crit Care Med 2006;34:800-806.

18 Saotome T, Endo Y, Sasaki T, Tabata T, Hamamoto T, Fujino K, Andoh A, Eguchi Y, Tani T, Fujiyama Y: A case of severe acute pancreatitis treated with CTR-001 direct hemoperfusion for cytokine apheresis. Ther Apher Dial 2005;9:367-371.

19 Oda S, Hirasawa H, Matsuda K, Nakanishi K, Matsuda K, Nakamura M, Ikeda H, Sakai $\mathrm{M}$ : Cytokine adsorptive property of various adsorbents in immunoadsorption columns and a newly developed adsorbent. Blood $\mathrm{Pu}$ rif 2004;22:530-536.

20 Watanabe E, Hirasawa H, Oda S, Matsuda K, Hatano M, Tokuhisa T: Extremely high interleukin- 6 blood levels and outcome in the critically ill are associated with tumor necrosis factor- and interleukin-1-related gene polymorphisms. Crit Care Med 2005;33:8997. 